\title{
A Study on the Spread of Ethnic Minority Traditional Legends in the New Era: Taking the Video Game "Nishan Shaman" as an Example
}

\author{
Aligeng ${ }^{1}$ \\ ${ }^{1}$ School of International Studies, Shaanxi Normal University, Xi'an, Shaanxi, China \\ aliegng@qq.com
}

\begin{abstract}
Currently, "Nishan Shaman" is one of the few music video games based on ethnic minority folklore in China. The game is based on the Manchu shaman legend Nishan Shaman and put Nishan in the underworld looking for the soul of a child as the main line of the story. The Manchu legend and Manchu culture are integrated into the narrative process of the game so as to make the game space full of Manchu shaman culture. This "packaging" of the traditional culture of ethnic minorities in modern video games provides the possibility for ethnic minority culture to enter into the younger generation and the general public, and it is a new way for ethnic minority traditional culture to spread in the new era.
\end{abstract}

Keywords: "Nishan Shaman", legend Nishan Shaman, Manchu, video games, cultural transmission

\section{传统少数民族传说在新时期的传播研究一一以尼山萨 满》电子游戏为例}

阿力更 ${ }^{1}$

${ }^{1}$ 陕西师范大学外国语学院, 西安, 陕西, 中国
aliegng@qq.com

\section{摘要}

《尼山萨满》是目前我国国内为数不多的以少数民族民间传说为蓝本创作而成的音乐类电子游戏, 该游戏基于 满族萨满传说《尼山萨满传》, 将尼山在冥界寻找幼童灵魂作为故事主线, 使满族传说和满族文化融合进游戏 的叙事进程，建构了一个充满满族萨满文化氛围的游戏空间。这种将少数民族传统文化加以现代电子游戏而进 行的 “包装”, 为少数民族文化走进青年一代和大众提供了可能, 是少数民族传统文化在新时期传播的新途径。

关键词: 《尼山萨满》; 《尼山萨满传》; 满族; 电子游戏; 文化传播

\section{1.前言}

中国是多民族聚居国家，拥有丰富且炫丽的民族 文化资源, 自上世纪 50 年代我国大力促进少数民族 文化挖掘和保护工作以来, 先后有新疆维吾尔木卡姆 艺术、蒙古族长调、呼麦、藏戏、玛纳斯和格萨 (斯)
尔等入选联合国教科文组织非物质文化遗产名录。 2004 年新闻出版总署发出《关于实施“中国民族网络 游戏出版工程”的通知》, 该通知指出将在 2004 年至 2008 年出版 100 种自主开发的大型民族网络游戏出 版物，凡是被列入“中国民族网络游戏出版工程”的选 题都将获得新闻出版总署和有关部门的支持，首批被 选入“网络游戏出版工程”的游戏就包括以三国时期 
为背景的《傲视 online》、以《封神演义》为蓝本的 《封神榜》和以中国武侠文化为基础的《功夫 online》 等。从国家对民族文化的保护性措施可以看出, 近年 来随着国家对于民族文化宣传和开发的重视, 将民族 传统文化与现代科技相融合成为了民族文化发展的 新方向。

《尼山萨满传》是满族传说的典型代表, 但其却 一直隐于大众视野之外，尤其对于 90 后、00 后和 10 后这样的青年一代, 类似《尼山萨满传》这样的传统 少数民族传说更是与他们所处的时代严重脱节。《尼 山萨满》游戏是一款结合了满族传统剪纸艺术、满族 萨满传说和民族音乐的音乐打击类游戏, “由 6 名毕 业生历时五个月制作, 由腾讯游戏学院和 Next Studio 共同孵化”,[1]，2018 年《尼山萨满》在 iso 和 WeGame 平台上架, 从其上架以来就受到了众多游戏玩家的追 捧, 同时也受到了业界的好评, 该游戏获得了 App Store 和 Tap Tap 的首页推荐, 其在 App Store 已经累 积了 1.46 万的下载量, 游戏评分为 4.8 分。《尼山萨 满》游戏的创作反映出了新时期青年一代对于中国少 数民族传统文化的接受与理解, 这种使用少数民族传 说为主题结合新型科技手段制作出来的游戏作品为 新时期少数民族文化的传播提供了新的路径, 同时该 游戏所受到的关注与追捧也说明了少数民族文化通 过电子游戏这种方式走向青年一代以及走向普通大 众的可能。

\section{2. 《尼山萨满》游戏简介}

《尼山萨满》是一款音乐打击类手游, 整个游戏 以名为尼山的女萨满寻回一名幼童的灵魂的冒险故 事为线索, 该游戏共分为五关, 每关都有一个主题场 景, 尼山手中的鼓是击退冒险过程中各种鬼怪的主要 武器, 游戏玩家通过控制尼山击鼓的节奏来通关。第 一关的名称为《村落》, 在整个游戏中起着介绍故事 背景的作用, 本关主要以尼山的师傅在村落中历练尼 山的本领为主要内容, 交代了尼山作为鹿灵带给北方 先民的一名女婴的传奇身世, 同时, 本关也是游戏玩 家掌握如何控制尼山击鼓节奏的入门关卡。

在尼山通过师傅的考验后, 游戏正式进入尼山寻 找幼童灵魂的故事线。游戏的第二关名为《冥河》, 主要讲述了尼山渡过冥河的场景, 渡过冥河是尼山在 冥界冒险的第一段旅程, 尼山通过使用神鼓击退冥河 中魔鱼的攻击, 完成第二关。紧接着尼山进入到第三 关《鬼城》, 在本关中尼山需要打败不断进行攻击的 鬼火和小鬼。第三关末尾, 尼山受到了来自师父的攻 击, 尼山的师父就是取走幼童灵魂的恶灵, 在师父的 攻击下尼山的性命危在旦夕, 至此第三关结束。命县 一线的尼山进入了第四关《圣域》, 第四关以群山中 的岩画为场景, 在尼山的性命苃苃可危之时, 岩画上 的鹿神显灵带领着尼山前往最终的目的地福神殿。

《福神殿》是《尼山萨满》游戏的最后一关, 本关以 福神殿为场景展示了尼山与化身福神的师父间的较 量, 福神是整个游戏中除去鬼怪外对尼山找回幼童灵
魂的最大阻碍, 也是游戏最后的 Boss, 在击退福神后 尼山找到了幼童的灵魂，将幼童的灵魂带回到人间， 幼童与父母最终得以团聚, 尼山也从此名声远扬。

马林诺夫斯基在《文化论》中指出知识、巫术和 宗教是文化的几种架构, 而游戏、游艺、运动和艺术 的消遣则可以把人从常规中解放出来, 消除文化生活

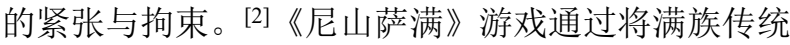
民间传说《尼山萨满传》与电子游戏相结合, 摆脱了 从书面材料或者融入满族文化环境才能获得满族民 间传说知识的束缚, 在轻松愉悦的环境中让玩家切身 体验到了满族萨满文化的魅力。成年人的游戏除去娱 乐功能外, “对于社会组织; 对于艺术, 技巧, 知识, 和发明的发展; 对于礼仪的伦理规律, 自尊心理, 及 幽默意识的培养, 也都有很大的贡献”[3]。《尼山萨满》 游戏不仅可以使玩家跟随尼山进行拯救幼童的冒险 之旅, 更能够通过游戏这种隐性传播途径促进大众对 于满族文化的了解。在闯关过程中, 玩家需要集中注 意力于游戏构造的萨满世界，这种身心的投入更能够 在短时间内向玩家输入充满满族文化元素的信息, 电 子游戏的互动性与沉浸感让玩家获得了不同于电影 和文学的故事体验, 为人类体验故事情节提供了更多 的可能, 因此电子游戏有望成为传播文学作品的新载 体 ${ }^{[4]}$ 。

\section{3. 《尼山萨满》游戏中的满族萨满文化建构}

《尼山萨满》游戏从多维度和多角度对满族萨满 文化世界进行了建构, 多维度是指从听觉、视觉和触 觉这三维建立起立体的满族萨满文化世界, 多角度是 指从民族文化元素、人物特征和情节发展线索这三个 角度丰富满族萨满文化的内容, 基于这种多维度和多 角度的建构《尼山萨满》成功的将满族萨满文化与电 子游戏融合在一起，使玩家既获得了丰富多彩的游戏 娱乐体验，又达到了传播满族文化的目的。

\section{1. 多维度的满族萨满世界}

现今的电子游戏往往具有画面制作精良、背景音 乐独具特色和玩家操控流畅等特点, 这三方面同时也 决定着一款游戏是否为玩家所喜爱, 所以游戏画面、 背景音乐以及可操作性构筑起电子游戏的主干。游戏 的画面、音乐和操作性对应着玩家的视觉、听觉与触 觉, 《尼山萨满》游戏中对于满族萨满世界的建构也 体现在视觉、听觉与触觉三个方面。

视觉是玩家对电子游戏的第一感受, 《尼山萨满》 在游戏图画的创作中引入了传统的满族剪纸艺术作 为人物形象和画面的构成工具。剪纸是我国民间普遍 存在的艺术形式, 生活在我国东北地区的满族人中流 传有独具特色的剪纸艺术, 满族剪纸往往以萨满教、 民间传说、神话故事等为题材进行创作，具有“以直 线为主、曲线为辅, 形象追求神似, 不拘泥于具体形 态, 善于抓住对象的基本特征, 大胆运用夸张的表现 手法”[ [] 的艺术特征。萨满信仰是满族文化的重要组成, 
在萨满仪式的过程中往往使用剪纸的方式将各种具 有萨满教象征意义的图画粘贴于法器和服饰上。萨满 巫师也使用剪纸实现与鬼神的沟通, 例如满族剪纸的 代表性样式拉手娃娃、嬤嬤人等, 都是通过萨满巫师 剪出的图案变为神的替身, 在萨满仪式中使用这些剪 纸作品实现了人神间的沟通。剪纸艺术因其删繁为简、 突出基本特征的创作手法而能够“将神的形象加以突 出、强化、形象化”,[6], 因此在满族文化中通过剪纸能 够将萨满教中的神灵形象化，更加方便人神间的沟通。

听觉是玩家接触到《尼山萨满》游戏的另一重要 体验, 游戏的背景音乐不仅能够帮助游戏玩家迅速进 入剧情, 还能够营造游戏的氛围让玩家融入到游戏所 设定的情境中。《尼山萨满》作为一款音乐类电子游 戏, 音乐不仅充当着烘托游戏氛围、刺激感观体验的 重要元素, 还起着勾勒故事情节、推进游戏进程的重 要作用。例如在第一关《村落》中, 游戏音乐旋律缓 和、节奏明快, 玩家容易根据音乐的起伏敲击出正确 的鼓点。随着尼山冒险历程的推进, 游戏音乐旋律趋 于紧张, 尼山手中敲击的鼓点也逐渐密集, 其中还穿 插有男声的低吟和女生高六的唱腔, 营造出了原始、 神秘的萨满世界。音乐作为《尼山萨满》塑造故事情 节的重要手段, 突出体现于《圣域》一关, 该关尼山 因受到师父的打击而命垂一线, 当玩家进入到《圣域》 一关就能够听到管风琴所发出的哀转低沉的声音, 随 后配以二胡幽怨的琴声和缓慢的击鼓速度, 将玩家即 刻代入到尼山危难的情景之中。《尼山萨满》在不同 关卡配合不同情景而展示的背景音乐, 让玩家在听觉 感知的触动下跟随着音乐的起伏而体验尼山一路寻 找幼童灵魂的冒险历程, 从而使得《尼山萨满》脱离 了音乐打击类游戏仅仅以依靠卡点通关为游戏目的 的单一特征, 将音乐有效的融合进游戏叙事过程, 在 听觉上促使玩家更加深入的进入游戏构造的萨满世 界。

触觉是《尼山萨满》游戏最基本也是最核心的构 成要件, 玩家需要根据音乐节奏通过不断的击打屏幕 而控制尼山手中击鼓的节奏以便达到通关的目的。在 满族萨满音乐中, 手鼓和萨满神歌有着密切的共生关 系, 这两者均为满族萨满文化的载体, 手鼓是萨满巫 师做法时的重要法器, 萨满巫师口中一边吟诵神歌, 一边还要击打手中的神鼓配合着神歌的曲调产生出 具有韵律的鼓声。满族民间还流传有手鼓的传说, 相 传从前满族的先人居住在大山之中, 突然有一天大山 开始向外喷火, 喷出的火花将大山融化、将河水烤干, 人们眼看就要干饿而死, 于是众人求助于天神, 天神 说多伦山的多伦玛发有救火的办法, 于是一名满族青 年达木鲁自告奋勇去寻找多伦玛发。在寻找多伦玛发 的过程中, 达木鲁偶遇到一位将要饿死的老人, 出于 好心，达木鲁救下了这位老人并一路对老人好生照顾。 一天, 老人看到山涧边有一棵梨树, 老人渴的厉害想 要吃梨, 达木鲁不顾个人安危爬到梨树上摘梨, 正在 达木鲁刚爬上梨树摘梨之时, 树枝突然折断了, 达木 鲁以为自己这下必死无疑, 不料自己竟掉在了老人的
怀里, 手中的梨变成了一条柳枝和一面手鼓, 这位老 人便是他要寻找的多伦玛发。多伦玛发告诉达木鲁, 种下柳枝便可发出神水, 敲响手鼓便可盖住大山。达 木鲁按照多伦玛发的指点回到家乡使用柳枝和手鼓 扑灭了山中的大火, 帮助人们回到了从前安居乐业的 日子。从该则手鼓的传说可以看出，神鼓在满族民间 信仰中的存在源远流长, 是满族民间信仰的重要象征 物。《尼山萨满》中采用玩家敲击屏幕而操纵尼山手 中的神鼓这一触觉体验, 使玩家切身融入到满族信仰 文化中, 玩家化身成为了应和神曲而击鼓的萨满巫师。

\section{2. 多角度的满族萨满世界}

《尼山萨满》游戏主要从满族文化元素、人物特 征和情节发展这三个角度对游戏中建构的萨满世界 进行了进一步的扩展和丰富。《尼山萨满》充斥着丰 富的满族文化元素, 如游戏的开始界面 (图 1) 就包 含有满语、中文和英文三种语言写成的“尼山萨满”词, 在解说故事梗概的过程中所使用的解说词也由满 语诵读。另外, 无论游戏的主角尼山还是尼山一路需 要击退的鬼怪均可以在满族民间传说中找到其踪迹。

《尼山萨满》游戏的叙事脉络遵循着满族传说《尼山 萨满传》的大致情节, 将尼山萨满拯救巴彦之子塞尔 古岱.费扬古的过程整合成《尼山萨满》的叙事框架, 使得传统的满族传说在现代电子游戏中获得了重生。

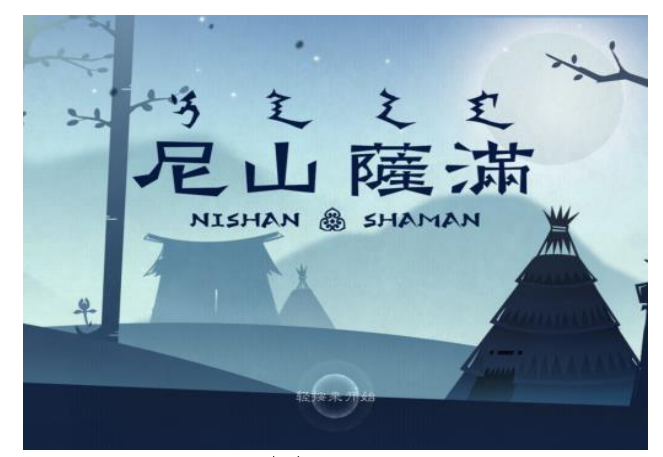

图 1

拥有众多满族文化元素是《尼山萨满》游戏突出 民族特征的一项重要手段。这些满族文化元素主要表 现在尼山萨满持有的萨满神鼓和出现的各种鬼怪形 象两个方面。萨满神鼓是萨满在做法时使用的最常见 也是最主要的法器, 在施展法术的过程中, 萨满通过 击打鼓面将自己的法术释放出来, 从而实现人与神的 沟通。“神鼓的声音, 象征着宇宙变化和呼吸的声音。 神鼓又象征是乘载着宇宙万物的广宇, 海涛, 风雷, 闪电, 以及宇宙和世界变幻、生命的孕生和死亡, 全 都囊括和演绎在小小的圆神鼓上面。"[]]神鼓既是萨满 迎送诸神的法器, 又是帮助萨满魂游宇宙、跨山度海 的帮手。神鼓具有的象征意义和法力被应用到《尼山 萨满》游戏当中, 神鼓是玩家在游戏中操控的对象, 神鼓所发出的鼓点决定着玩家是否顺利通过关卡，玩 家通过操纵尼山手中的神鼓化身成为了游戏中历尽 万难的萨满尼山。 
《尼山萨满》游戏中选取了满族文化中具有代表 性的民族图案作为每关尼山所需面对的鬼怪, 其中包 括有柳枝 (图 2)、鱼、龙、蒙高勒代 (图 3)、色勒 图 (图 4)、火星、神鸟和福神 (图 5) 等, 完成每个 关卡后还有与本关相关的图鉴, 在图鉴中附有对各种 图案的介绍以及所参考的文献。满族民间的萨满信仰 决定着满族人民对自然万物的崇拜, 这些崇拜物也逐 渐演变成为各路神灵，如天神、火神、祖先神、佛多 妈妈 (柳枝娘娘) 等。柳枝在满族民间往往与丧葬和 祭奠仪式紧密相连, 在满族信仰中柳枝是人的始祖, 人是柳的子孙, 如在上坟祭祖时们需要在坟上插柳, 以表示家族后继有人 ${ }^{[8]}$ 。对于鱼、神鸟、龙等动物的 崇拜则源于满族萨满信仰的“万物有灵观”, 鱼、鸟、 龙等动物是满族文化中的神兽, 在《尼山萨满传》中 就写有尼山一入冥界看到“神兽跑着, 鸟神飞着, 蛇 仙蟒神扭着, 都像旋风似的行走” ${ }^{[9]}$ 的场景。蒙高勒代 和色勒图是《尼山萨满传》中冥界的鬼怪, 蒙高勒代 是阎王的亲戚, 负责抓走塞尔古岱. 费扬古的灵魂, 色勒图是看守鬼门关的小鬼。《尼山萨满》游戏通过 将萨满神灵转换成为鬼怪, 强调了它们在满族萨满信 仰中的重要性, 同时也借助这些鬼怪的形象突出了游 戏具有的民族性特征。

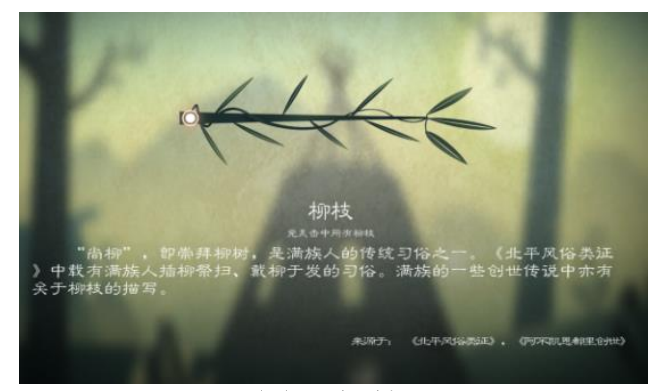

图 2 柳枝

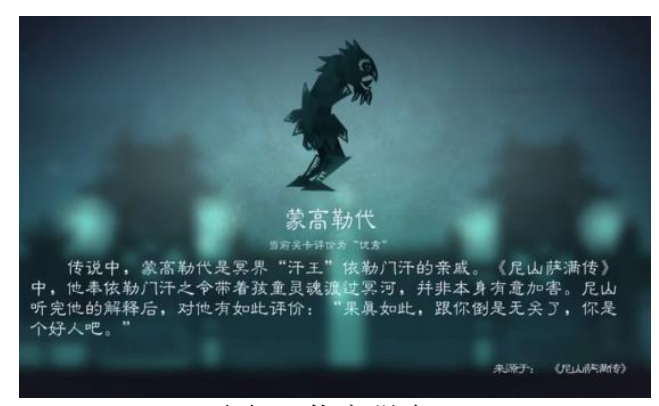

图 3 蒙高勒代

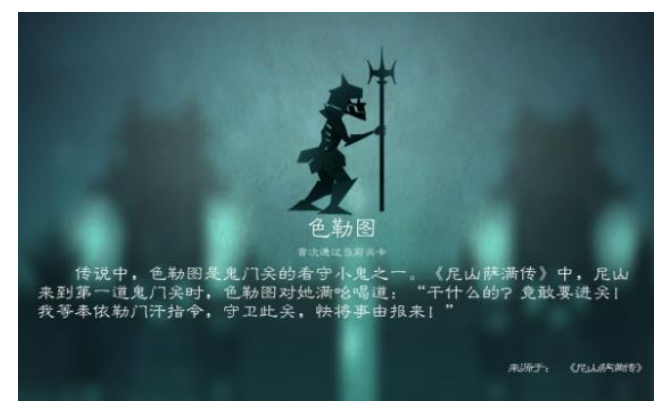

图 4 色勒图

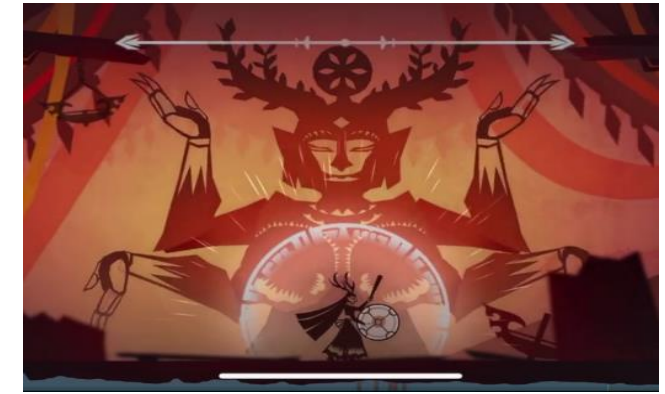

图 5 福神

《尼山萨满》中的人物也是游戏用来丰富萨满世 界的重要角度。在游戏中除去尼山是绝对的主角外, 还有鹿神和福神两个对尼山找回幼童灵魂成功与否 起着决定性作用的人物。鹿神是满族萨满信仰的代表, 被称为“抓罗妈妈”, 相传满族的鹿神是一个善骑好射 的姑娘, 她能够听懂鹿的语言, 能管理鹿群, 鹿曾经 救过这位姑娘的命, 还帮助她战胜过入侵的部落, 在 鹿向这位姑娘传授神力后, 她长出了鹿角, 成为了鹿 神。在满族萨满祭祀中, 萨满做法所用的法器除了神 鼓、腰铃, 还要带上神帽, 这神帽之上就插有两只鹿 角, 据说插有鹿角的神帽可以镇妖除邪。[10]在《尼山 萨满》游戏中, 鹿神沿袭着满族萨满文化传统, 是尼 山历险的保护神 (图 6), 当尼山命悬一线奄奄一息 之时, 是鹿神将尼山从危难中救出并帮助尼山顺利来 到了最后一关福神殿。福神在满族民间信仰中是保护 地方和平安定、避免野兽或恶灵侵扰的善神, 为了祈 求家庭的安定富足, 满族家庭会定期向福神祭拜。《尼 山萨满》游戏中福神是贯穿于游戏叙事始终的神祗, 幼童的灵魂被恶灵掳走就是因福神被破坏而起, 最终 尼山要战胜的最大敌人也是福神。《尼山萨满》通过 使用鹿神和福神两位满族民间信仰中重要神灵的形 象, 并将它们贯穿于游戏始终, 使得整个游戏保持在 神话传说的氛围中。

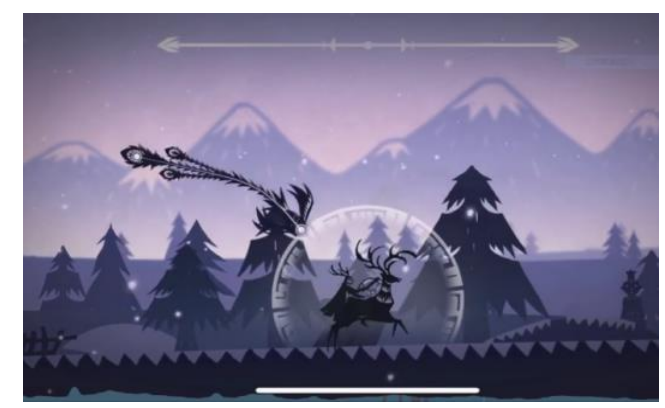

图 6 鹿神与尼山

在游戏中将《尼山萨满传》的故事情节融合进游 戏叙事是《尼山萨满》游戏构建萨满世界的又一重要 角度。前文已述，一般的音乐打击类游戏注重音乐对 玩家的感官刺激, 将游戏体验的重点集中于玩家的听 觉感受, 而《尼山萨满》同传统的音乐打击类游戏最 大的不同就在于添加了游戏自有的叙事线索, 音乐打 击成为了游戏进行的工具, 游戏的最终目的是通过打 击而讲述尼山萨满“招魂”的故事, 因此《尼山萨满》 中将故事情节发展设定为萨满尼山进入冥界寻找幼 
童灵魂, 这一主干情节支撑起了整个游戏浓郁的满族 萨满文化特征。萨满是沟通人神世界的使者, 萨满的 灵魂出空从而进入神界, 将凡人的愿望传达给神祇是 萨满的主要功能, 西方著名萨满教学者埃利亚德在 《萨满教——古老的昏迷方术》中就将灵魂是否能够 离开肉体进而上升到天界或是下降到下界作为判断 一个巫师是否可以称之为萨满的标准。《尼山萨满》 的故事情节抓住了萨满具有的最基本特质, 将萨满 “招魂”的主题通过游戏叙事展现了出来。萨满“招魂” 不仅能够给游戏增加神秘感、激发玩家的探索欲, 还 能够将萨满的最基本特征展示出来, 让玩家在游戏体 验的过程中复现了萨满教的教义教理。

\section{4. 《尼山萨满》对神话的改编和发展}

游戏是一种在人类社会中早已存在的社会活动, 电子游戏作为游戏的一种新形式, 其中包含的剧情、 角色、音乐和符号等文化要素通过电子游戏的整合而 成为一种新的文化从而拥有更广大的受众。玩家在电 子游戏中“不再是看别人的故事, 而是在体验自己的 故事”, [11]，因此在电子游戏中，玩家也是神话叙事的 主人公, 从而将从前知识的被动接受模式改为主动探 索。《尼山萨满》在游戏中将满族神话人物尼山、萨 满传说和萨满符号融合进游戏的空间, 使得满族萨满 文化拥有了新的生命, 游戏玩家借助游戏获得了对满 族萨满文化的认知, 同时游戏也对传统的神话传说进 行了适度的改编, 使其更加符合现代人的文化认知, 让传统文化通过电子游戏在新时期获得了新发展。

《尼山萨满》游戏中主要选取了《尼山萨满传》 中尼山拯救塞尔古岱. 费扬古灵魂的故事, 尼山的冒 险历程分为 《冥河》、《鬼城》、《圣域》和《福神殿》 四个关卡, 浓缩了尼山萨满传说的核心部分, 也将满 族萨满传说的概貌呈现给了玩家, 可以说《尼山萨满》 是《尼山萨满传》的精简版本, 其中保留了传说中尼 山过二道河、闯阎王城的情节, 玩家在闯关的过程中 能够体验到尼山萨满传说的主要故事内容。虽然《尼 山萨满》是仿照《尼山萨满传》而制作的电子游戏, 但《尼山萨满》游戏对原著进行了适应当今时代特征 的改编和发展, 使故事的叙事更加吸引玩家, 引人入 胜。《尼山萨满》游戏中对于故事梗概交代如下:

相传, 鹿灵带给北方先民一名女贞, 女贞天生灵 力, 被先民封为神贞, 并取名为“尼山”。尼山的神力 日益显现, 凭借击鼓便能通万灵、驱邪崇, 她的师父 是福神的信徒, 相信福神掌管着世间万物的生命。尼 山成年时会受到师父的考验, 若能通过, 便可去往部 族外历练。

傍晚, 一个孩童在嬉戏时, 无意冒犯了神明, 图 腾受损, 灵力逸散, 恶灵从生。恶灵夺走了孩童魂魄, 孩童神魂离体, 回天难期。父母悲痛欲绝, 恳求尼山 帮助。尼山感其诚心, 师父的教诲涌上心头, 于是她 戴上鹿角帽, 决定深入绝地, 救回孩子。在众人的簇 拥下, 她击鼓而舞, 神魂出体, 坠入幽冥。
后来，尼山将孩童的灵魂带回给他的父母，她走 向鹿灵, 续写作为萨满的传奇。

游戏对于尼山萨满传说的改编首先表现在对孩 童丢魂的解释上, 《尼山萨满传》中孩子丢魂的原因 是阎王看中了孩子的才智, 将孩子的灵魂取走, 希望 将孩子的灵魂留在冥界充当自己的儿子，而在游戏中， 幼童丢魂的原因是因为破坏了村里的图腾, 致使恶灵 将其灵魂取走。其次, 《尼山萨满》中引入了尼山萨 满传说并不存在的福神和鹿神, 并将庇佑百姓生活安 定幸福的福神化作尼山寻找幼童灵魂的最大阻碍, 对 福神的角色进行了重新演绎, 增加了游戏的趣味性。 最后, 《尼山萨满》改变了《尼山萨满传》的悲剧性 结局, 在传说中尼山因在冥界没有将丈夫的灵魂带回 到阳间而受到婆婆的报复，最终被关押在井中的皮箱 内, 失去了自由。游戏却给予了尼山一个光明的未来, 在其将幼童的灵魂带回到人间后赢得了大家的尊敬, 成为了名扬四方的萨满巫师。

神话传说反映着“原始先民对人类生殖、万物起 源、自然现象与社会生活的认识和探索”[12]，强调人 生哲理、生活哲学、道德教化等社会功用, 而游戏作 为一种主要提供娱乐、供人放松的社会活动, 在塑造 意识形态和启迪心智等方面并不是游戏的主要作用。 因此, 作为电子游戏的《尼山萨满》, 在转变萨满传 说的过程中适当的去掉了传说具有的严肃性而增强 了其中的娱乐性，进而出现了游戏中恶灵掳走幼童灵 魂、鹿神拯救尼山和尼山与福神对抗等冲突性较强的 桥段, 其中表现出来的善与恶的交锋能够让玩家很快 接受游戏包含的故事情节，也能够在短时间内对尼山 产生共情和好感，并且战胜恶势力、营救幼童灵魂的 任务设定也能激发玩家的正义感，促使玩家能够坚持 闯过各个关卡。除去娱乐性的增加, 《尼山萨满》也 抛弃了传说带有的封建专制思想，在《尼山萨满传》 中虽然尼山最终将塞尔古岱. 费扬古的灵魂带回人间, 拯救了他的性命, 但尼山也没有摆脱作为一名生活在 封建社会中女性的悲惨命运, 以被关押在井中的皮箱 内作为结尾。《尼山萨满传》中对于女萨满尼山的人 物设定, 反映了其创作年代女性的生存境遇, 而在《尼 山萨满》游戏中, 游戏的主创人员让尼山摆脱了丈夫、 婆婆和官府的束缚, 塑造了一个为人称道的新女性形 象。尼山形象的转变折射出了神话传说文本因社会进 步而发展的变化规律, 也折射出了现代青年对传统文 化的理解和转变。

\section{5. 结论}

《尼山萨满》是现今中国电子游戏市场中涌现出 的少有的以少数民族传说为创作蓝本的电子游戏, 其 通过对满族萨满传说《尼山萨满传》进行改编, 使满 族的萨满文化在电子游戏中焕发了新的光彩。《尼山 萨满》不仅是一款让人耳目一新、制作精良的音乐打 击类游戏, 还将萨满传说中的故事情节融合进游戏进 程, 增加了音乐类游戏的叙事模式, 让游戏兼具了娱 乐性与知识性, 为少数民族传统文化在新时期的传播 
提供了新的路径。此外, 由于电子游戏玩家群体的年 轻化和国际化, 《尼山萨满》对少数民族神话传说的 改编为这些神话传说走进 90 后、00 后一代提供了可 能, 也为少数民族神话传说的国际化发展做出了尝试。

\section{项目基金}

本文为中央高校基本科研业务; 陕西师范 大学博士研究生自由探索项目《英国蒙古学家 查尔斯·鲍登及其学术思想研究》(2019TS092) 的阶段性成果之一。

\section{REFERENCES}

[1] Tencent WeGame. (2018) Nishan Shaman. https://www.wegame.com.cn/store/2000482/Nishan Shaman.

[2] Malinowski, Bronislaw. (2002) The Scientific Theory of Culture. Trans.by Fei Xiaotong. Huaxiao Publishing House, Beijing. pp.80.

[3] Malinowski, Bronislaw. (2002) The Scientific Theory of Culture. Trans.by Fei Xiaotong. Huaxiao Publishing House, Beijing. pp.83.

[4] Yang, Y. (2019) The Theoretical Construction and Practice of Story-based Video Games. Social Science Front, 9:262-266.

[5] Bi, D. (2018) Book Series of Intangible Cultural Heritage in Northeast China: Folk Craftsmanship. Northeastern University Press, Shenyang. pp.87.

[6] Wang, C. (1988) Manchu Paper-cutting and Shamanism. Manchu Minority Research, 4:pp.94-95.

[7] Fu,Y. (2000) Shamanism. Liaoning People's Publishing House, Shenyang. pp. 271-272.

[8] Li, X ed. (2007) National Festivals and National Music. Inner Mongolia Culture Publishing House, Hailaer. pp.54.

[9] Zhang, H Trans. (2007) Nishan Shaman. Yingyu Culture, Taibei. pp.35.

[10] Meng, H. (2013) Myths and Beliefs of Deer God. In:Ye, S. (Eds.), Selected Essays on A Century of Chinese Mythology. Shannxi Normal University Press, Xi'an. pp.1068.

[11] Internet Development Research Institution. (2019) Gameology. China Renmin University Press, Beijing. pp.147.

[12] Gong, G. (2016) New Theory of Aesthetic TrasnsIation. Shanghai Jiao Tong University Press, Shanghai. pp.151. 